\title{
Strategies for the Use of Natural Products for Weed Management ${ }^{1}$
}

\author{
Stephen O. Duke, * Agnes M. Rimando, Scott R. Baerson, Brian E. Scheffler, \\ Eiji OTA $^{\dagger, *}$ and Regina G. BELZ ${ }^{\dagger \dagger}$ \\ Natural Products Utilization Research Unit, Agricultural Research Service, United States \\ Department of Agriculture, P. O. Box 8048, University, MS 38677, USA \\ ${ }^{\dagger}$ Bio-Technology Group, Advanced Technology Laboratory, KUBOTA Corporation, \\ 5-6, Koyodai, Ryugasaki, Ibaraki 301-0852, Japan \\ ${ }^{+\dagger}$ Department of Weed Science, University of Hohenheim, Institute for Phytomedicine \\ 360, Otto-Sander-Strasse 5, 70599 Stuttgart, Germany
}

(Received June 17, 2002)

\begin{abstract}
Natural products have not been utilized as extensively for weed management as they have been for insect and plant pathogen management, but there are several notable successes such as glufosinate and the natural product-derived triketone herbicides. The two fundamental approaches to the use of natural products for weed management are: 1) as a herbicide or a lead for a synthetic herbicide and 2) use in allelopathic crops or cover crops. New technologies, such as molecular biology, provide tools for expanding the use of natural products in weed management. Strategies for implementation of these approaches are discussed, along with examples.
\end{abstract}

Key words: allelochemical, allelopathy, herbicide, natural products, phytotoxin, weed management.

\section{INTRODUCTION}

Unlike synthetic pesticides, natural products can be either biosynthetically produced in the crop to be protected or used directly as a pesticide or a pesticide lead. Thus, there are two fundamental approaches to the use of natural products for weed management. The first is to use them as allelochemicals in allelopathic crops or cover crops to manage weeds, in much the same way that natural products have been manipulated in crops to manage insects and plant pathogens. In many ways, this is a type of biocontrol, especially when a cover crop is used to control weeds in a crop. The advent of transgenic methods to manipulate secondary product production in plants offers a powerful new tool in implementing allelopathy approaches to weed management.

The other strategy is to use them directly as herbicides or as leads for synthetic herbicides. Natural products have been extremely lucrative sources of pharmaceuticals and, to a lesser extent, pesticides. Compared to use of natural products as insecticides and fungicides, natural

* To whom correspondence should be addressed.

E-mail: sduke@ ars.usda.gov

\# Present address: 6-33-5-508 Kiba-cho, Minato-ku, Nagoya, Aichi 455-0021, Japan

${ }^{1}$ A plenary lecture at the 27 th annual meeting of the Society. products have not been utilized as extensively for weed management, but there are several notable successes. Modern technology may increase their use in weed management. Natural products offer rapid access to novel chemical structures often with new molecular target sites. ${ }^{1)}$ Furthermore, there is a perception that natural products are safer than synthetic pesticides, and indeed, their environmental toxicology profiles are generally more benign than those of synthetic herbicides. The topic of natural products in weed management has been previously reviewed. ${ }^{2-4)}$ This review updates and expands this topic, covering new strategies and technologies for exploiting natural products in weed management.

\section{USE OF NATURAL PRODUCTS IN CROP ALLELOPATHY}

Allelopathy can negatively or positively impact crop production, but most of the literature deals with crop losses due to allelopathy. ${ }^{5)}$ Allelopathy of weeds can be a component of their interference with crops. Allelochemicals in some crop residues can eventually lead to autotoxicity in continuous monoculture cropping systems, reducing crop yield. Likewise, allelochemicals have been implicated in reduced yields of certain crops planted after certain other crops. These processes have 
been described in several studies, ${ }^{5)}$ although few of these studies conclusively determine the allelochemical contribution to crop losses. Fewer studies have focused on the potential for allelopathic crops to control weeds.

Allelopathic cover crops and crops are an attractive strategy for the use of natural products to manage weeds. Theoretically, crops producing phytotoxic allelochemicals can interfere with competing weeds sufficiently to allow significant reductions in the use of other weed management options, including synthetic herbicides. The often relatively poor efficacy and resulting reduced yields, compared to herbicides, has limited this approach, except in specific situations. In rice, ${ }^{6)}$ wheat, ${ }^{7)}$ barley, ${ }^{8)}$ and a few other crops, geneticists and breeders have tried to produce allelopathic crops with which less herbicide might be used. This approach has not yet yielded a commercial variety with such a trait. Transgenic approaches to produce highly allelopathic crops might be more successful. We will discuss allelopathy and allelochemicals in several major cereal crops which are known to have allelopathic potential.

\subsection{Allelochemicals in grain crops}

The incidence of growth inhibition of certain weeds and production of phytotoxic symptoms by plants and their residues is well documented for many crops, including all major grain crops such as rice, rye, barley, sorghum, and wheat. To have a major impact on herbicide use, substitution of allelopathy for synthetic herbicides in these crops is the most promising approach.

All plants produce secondary metabolites that are phytotoxic to some degree, and in a small number of cases their release into the environment and capability of causing allelopathic effects towards a number of noxious weeds has been demonstrated. Crop allelopathy can be exploited for weed management by the release of allelochemicals from intact roots of living plants or decomposition of plant residues. In annual crops, root exudation of the phytotoxin by the crop is the preferred mechanism.

Barley allelochemicals. The success of barley (Hordeum vulgare L.) as a smother crop is attributed to physical competition as well as the direct release of allelochemicals. Phytotoxicity of barley residues has also been reported. ${ }^{9-12)}$ Two main categories of phytotoxic metabolites are claimed as the allelopathic agents in barley: phenolic acids and alkaloids.

Phenolic acids have been identified in residues ${ }^{13)}$ and root exudates ${ }^{14)}$ of barley. Chemical analysis of inhibiting compounds in barley residues detected ferulic, $p$ coumaric, vanillic, and $p$-hydroxybenzoic acids in aqueous extracts of straw and alcoholic extracts of roots. ${ }^{13)}$ The exudation of these compounds by intact roots along with benzoic, caffeic, o-coumaric, trans-cinnamic and gentisic acids has also been demonstrated. The competitiveness of $H$. vulgare cultivars was shown to be linked to a high exudation of total phenolics, whereby in particular $p$-coumaric acid was only detectable in root exudates of highly competitive cultivars and could therefore act as distinctive indicator for competitiveness of $H$. vulgare cultivars. ${ }^{14)}$ Although the phytotoxicity of phenolic acids is well known, their role and significance in the allelopathy of barley at the levels released is not clearly understood.

Two alkaloids, gramine and hordenine, (Fig. 1) have been identified in residues ${ }^{15-18)}$ and root exudates ${ }^{11,19)}$ of barley. Furthermore, gramine is found on the leaf surface and in leaf leachates of barley. ${ }^{17)}$ Gramine and hordenine have been isolated from shoot and root tissue of different Hordeum spp., whereby significant differences in the alkaloid contents between species, genotypes and cultivars appeared. The production of gramine was revealed to be under strong genetic control with usually higher contents in ancestral barley or $H$. vulgare landraces than in modern cultivars. Gramine content in ancestral barley reached up to $1.5 \mathrm{mg} / \mathrm{g}$ fresh weight $^{16,18)}$ and $>10 \mathrm{mg} / \mathrm{g}$ dry weight ${ }^{15)}$ in shoot tissue and up to $0.9 \mathrm{mg} / \mathrm{g}$ fresh weight in root tissue, ${ }^{16)}$ however some barley lines and $H$. vulgare cultivars produced virtually no gramine at all. Small fractions of up to $0.04-0.18 \%$ of the total gramine found in leaves were also present on the leaf surface and could be totally removed along with some inner gramine by artificial rain. ${ }^{17)}$ The implication of surface gramine in the allelopathy of barley has not yet been investigated.

The production of hordenine appeared to be highly responsive to stressful conditions. Hordenine contents in root tissues of Hordeum spp. varied between 133-327 $\mu \mathrm{g} / \mathrm{g}$ fresh weight, increasing up to $2.6 \mathrm{mg} / \mathrm{g}$ fresh weight under low light intensity. ${ }^{18)}$ Although the phytotoxicity of barley residues has been reported, and gramine and hordenine inhibited growth of various weeds, a correlation between the alkaloid content of residues or the actual release of alkaloids from residues and the inhibitory effect has not yet been investigated. In contrast, the inhibitory action of barley exudates against weeds has been demonstrated in several bioassays, ${ }^{11,19-21)}$ and the presence of gramine and hordenine in exudates of germinating seedlings and from intact roots was confirmed. Bioassays with synthetic analogues of gramine and hordenine at the levels quantified in exudates of germinating seedlings proved a phytotoxic effect. ${ }^{11,19,20)}$ Therefore, gramine and hordenine are believed to play a major role in the allelopathy of barley.

Hydroxamic acids, a group of major allelochemicals involved in the allelopathy of other Gramineae, could be detected as 2,4-dihydroxy-1,4-benzoxazin-3-one (DIBOA) (Fig. 1) in shoot tissue of wild Hordeum species, but not in cultivated barley. ${ }^{22)}$

Rye allelochemicals. Rye is believed to be the most suppressive cover crop among several small grains. ${ }^{23)}$ Numerous studies using rye as green manure or in cover 
crop mulch systems demonstrated a weed suppressive ability often as efficient as standard herbicide applications. ${ }^{10,24)}$ The contribution of allelopathy to the suppression of weeds in rye mulch situations is estimated to account for up to $63 \%$ reduction in weed biomass. ${ }^{25}$ ) Although investigations on the allelopathic activity of rye focus on residues, bioassays and field studies further determined root exudates as potential means by which competitive rye cultivars reduce weed growth. ${ }^{26-28)}$ The two main categories of phytotoxic metabolites claimed as the allelopathic agents are phenolic acids and cyclic hydroxamic acids.

The exudation of DIBOA and 2,4-dihydroxy-7methoxy-1,4-benzoxazin-3-one (DIMBOA) (Fig. 1) and the allelopathic potential of rye root exudates containing hydroxamic acids had been demonstrated. ${ }^{26,28)}$ Weed suppression by allelopathy of living rye proved to be significant under field conditions, with substantial evidence for the allelopathy being due to hydroxamic acids. A rye cultivar exuding large amounts of DIBOA reduced the total weed biomass by $83 \%$ compared to a wheat cultivar unable to exude hydroxamic acids and by $76 \%$ compared to Avena strigosa, a highly competitive crop, unable to produce hydroxamic acids. ${ }^{27)}$ Since the exudation of DIBOA by rye did not correlate with the content in roots, an active exudation depending on a specific regulation factor independent of type or content of hydroxamic acids in root tissues is assumed.

Although DIBOA and 2-benzoxazolinone (BOA) (Fig. 1) had been identified as the most active compounds in rye extracts, they accounted for only $12 \%$ of the total phytotoxicity. ${ }^{29)}$ Therefore, other phytotoxic compounds or additional transformation products may also play a role in the allelopathy of rye. BOA, for example, is rapidly degraded by microbial hydrolysis in non-sterile soils, ${ }^{30)}$ as well as by root-colonizing bacteria, ${ }^{31)}$ to the phytotoxic 2-amino-3 $H$-phenoxazin-3-one, which is further acetylated by root bacteria to 2-acetylamino- $3 \mathrm{H}$ phenoxazin-3-one. 2-Amino-3 $\mathrm{H}$-phenoxazin-3-one and its acetyl derivative are actinomycin analogues and, thus naturally occurring antibiotics, produced by a number of fungi and bacteria. Even though 2-amino-3 Hphenoxazin-3-one proved to be much more phytotoxic than its precursor BOA, its potential for increasing the allelopathic effect of rye is questionable, since the inhibitory effect of BOA in bioassays was significantly reduced by microbial transformation. ${ }^{31}$ This would explain the findings of decreasing phytotoxicity of rye mulch in non-sterile soil. ${ }^{32)}$

Rice allelochemicals. Allelopathic rice cultivars have been identified from field studies conducted over the past decade in approximately $3.5 \%$ of the accessions tested. ${ }^{33-35)}$ Allelopathy was demonstrated against the common rice weeds barnyardgrass (Echinochloa crusgalli), ducksalad (Heteranthera limosa), and redstem
(Ammannia auriculata). As a consequence, studies were conducted using laboratory assays that have been developed in order to study rice allelopathy in more controlled conditions. Examples of these assays include the plant box method, ${ }^{36)}$ relay seeding, ${ }^{37)}$ root exudate trapping system, ${ }^{38)}$ and petri dish assay. ${ }^{39)}$ In some cases, bioasssays have been utilized in the isolation of allelochemicals in rice.

Compounds that have been isolated from selected allelopathic rice varieties and identified as the putative allelochemicals are rather ubiquitous in plants, most of which are common phenolics, aromatic acids, long-chain hydrocarbons, fatty acids, and sterols. ${ }^{38,39)}$ More recently, the inhibitory activity of extracts from straw of four rice cultivars on barnyardgrass seed germination was reported $^{40)}$ and, again, activity was attributed to $p$ hydroxybenzoic acid (in cultivars Gin shun and Juma 10), $p$-coumaric acid (in cultivar Kasawala mundara), and ferulic acid (in cultivar Philippine 2). In another study, the activity of phenyl ammonia lyase was positively correlated with phenolic content of the aqueous extracts of the leaves of six allelopathic rice varieties. ${ }^{41)}$

Contrary to these findings, $p$-coumaric acid was demonstrated not to be the phytotoxic constituent from the allelopathic rice variety Taichung Native 1 root extract when tested against barnyardgrass. ${ }^{42)}$ Phytotoxic activity was found in other fractions that do not contain $p$-coumaric acid following bioassay-guided isolation. $p$-Coumaric acid was also found to be only weakly inhibitory against lettuce germination compared to the tricyclic diterpenes that were also isolated from rice husk of cultivar Koshihikari. ${ }^{43)}$ Olofsdotter et al. ${ }^{44)}$ also showed that phenolic acids are possibly not the allelochemicals in rice, based on measurement of tolerance to phenolic acids among traditional rice cultivars adapted to environments having inherently different phenolic acid concentrations. This study further showed that the maximum rate of release of phenolic acids during the first month of growth, the time period of greatest allelopathic activity, was approximately $10 \mu \mathrm{g} /$ plant/day. This rate would not provide concentrations of phenolic acids that would be at phytotoxic levels. Using LC/MS and ${ }^{1} \mathrm{H}$ and ${ }^{13} \mathrm{C}-\mathrm{NMR}$ spectroscopy, glucosides of resorcinol, flavones and hydroxamic acids were found as the allelochemicals in rice, negating an earlier study where common phenolic and fatty acids were identified as the rice allelochemicals. ${ }^{45)}$

The tricyclic diterpenes momilactones, oryzalexins, and ineketone (Fig. 1) are perhaps the secondary metabolites that are unique to rice. These compounds are growth inhibitors and are also phytoalexins. Momilactones A and B, and ineketone were isolated from the seed husk of Oryza sativa L. cv. Koshihikari, and were shown to be inhibitory towards lettuce root germination and growth of rice root. ${ }^{43,46)}$ Momilactone $C$ was 
later isolated from this cultivar as a minor component, and showed weak inhibitory activity towards lettuce seed germination. ${ }^{47)}$ Momilactones $\mathrm{A}$ and $\mathrm{B}$, and oryzalexins $\mathrm{A}$ and $\mathrm{C}$ were characterized as the allelochemicals from extracts of the straw of $O$. sativa cv. Haresugata. ${ }^{48)}$ Momilactone B exhibited the strongest inhibitory activity against the weed species tested, namely, Amaranthus lividus, Digitaria sanguinalis, and Poa annua. Whether or not the momilactones and oryzalexins are the true allelochemicals in rice requires further investigation. These compounds have been isolated from cultivars that are not known to be allelopathic. Furthermore, there are no reports on these compounds being isolated from the roots, nor on their release in the soil.

The isolation and identification of rice allelochemicals is yet to be fulfilled. Two lettuce growth-inhibiting substances were isolated from the neutral fraction of seedlings of $O$. sativa $\mathrm{cv}$. Nipponbare, but have not been characterized. Large-scale re-isolation of the active compounds is reportedly underway. ${ }^{49}$ In our laboratory, work is also continuing on the isolation of allelochemicals from Taichung Native 1, this being done in a bioassay-directed manner using 24-well plates.

Sorghum allelochemicals. Several Sorghum species are allelopathic, producing several phytotoxins, including sorgoleone (2-hydroxy-5-methoxy-3-[(Z,Z)- $8^{\prime}, 11^{\prime}$, $14^{\prime}$-pentadecatriene]-p-benzoquinone) (Fig. 1) and its phytotoxic analogues, as well as dhurrin, $p$ hydroxybenzoic acid and $p$-hydroxybenzaldehyde. ${ }^{50,51)}$ Sorgoleone and its analogues account for most of the phytotoxicity, since they represent as much as $80-90 \%$ of the content of droplets exuded from root hairs ${ }^{52)}$ and are the most phytotoxic compounds produced.

Of particular interest is that sorgoleone and its analogues are potent photosystem II inhibitors, ${ }^{53,54)}$ as well as sorgoleone being an excellent inhibitor of hydroxyphenylpyruvate dioxygenase (HPPD). ${ }^{55}$ The relative importance of these two modes of action in the field has not been determined. Dual molecular target sites are desirable to prevent the evolution of resistance.

2.2. Genetic manipulation of allelochemicals in crops

Despite the fact that these major crops produce allelochemicals, traditional breeding has not produced a cultivar of any of them which is sold as an allelopathic variety. While significant effort has been invested in the genetic manipulation of biosynthetic pathways producing phytoalexins and other secondary plant metabolites via transgenic approaches, similar efforts targeting allelochemicals are, to our knowledge, absent from the literature. However, strategies for transgene approaches to allelochemical manipulation have been proposed. ${ }^{56-58)}$ Part of the reason for the lack of progress in genetic manipulation of allelochemicals via biotechnology is the lack of identified gene sequences encoding the biosynthetic enzymes for these pathways. An exception is the

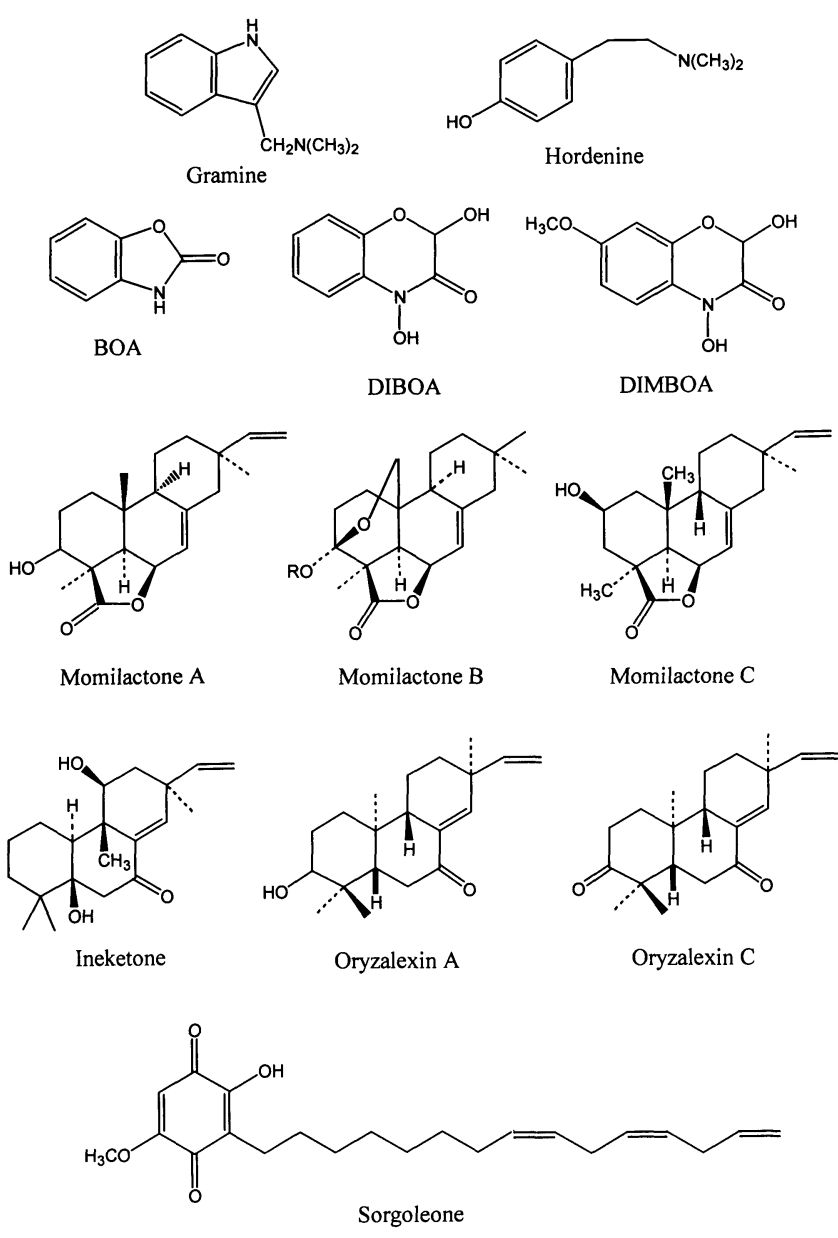

Fig. 1 Structures of some of the allelochemicals mentioned in the text.

hydroxamic acid pathway in maize leading to the formation of DIBOA, where all five genes required for biosynthesis have been identified. ${ }^{59)}$ In this example, a forward genetics approach was employed using the maize bx1 (benzoxazineless) mutant, ${ }^{60)}$ however this strategy is more suitable for a relatively well characterised genetic system and is impractical for the majority of allelochemical-producing species.

Alternative gene isolation strategies which are suitable for most allelopathic species include differential screening approaches such as suppression subtractive hybridization ${ }^{61)}$ or differential display. ${ }^{62)}$ While these techniques do not require the use of genetic mapping data to facilitate gene isolation, there is a requirement that the gene of interest exhibits differential expression under some predetermined set of experimental or developmental conditions. Alternatively, a species such as Artemisia annua, which includes biotypes both possessing and lacking peltate secretory glands ${ }^{63,64)}$ could be used as starting material for differential screens.

Frequently, secondary metabolites are produced by specific cell types within plants. Thus the corresponding genes involved in their biosynthesis may be specifically or 
preferentially expressed within those cells. If substantial amounts of the compound are produced, the system could be amenable to Expressed Sequence Tag (EST) analysis. $^{65)}$ Within specialised cells, such as root hairs or glandular trichomes, the genes involved may represent the most highly expressed mRNA species within that cell type, and can thus be identified within a random sampling of a few thousand sequences. Recently, this approach has been successful in the identification of genes involved in essential oil (monoterpene) biosynthesis in peltate glands of Mentha piperita. ${ }^{66)}$

A particularly intriguing target for genetic manipulation is the allelochemical sorgoleone, first identified in root exudates of Sorghum bicolor. ${ }^{67)}$ In addition, roots of $S$. bicolor can be propagated under soil-less conditions that either promote or inhibit root hair formation (M. Czarnota, unpublished). Thus, an excellent source of starting material is readily available for performing differential screens as described above. The observation that sorgoleone is the major component found in $S$. bicolor root exudates also suggests that an EST-based approach would be a logical strategy to pursue. Our laboratory has been actively pursuing the isolation of sorgoleone biosynthetic genes using both suppression subtractive hybridization as well as EST analysis. Highly purified root hair preparations can readily be obtained from S. bicolor (Fig. 2), and from this starting material a cDNA library was prepared for the development of a sequence database comprised of 5000 randomly chosen sequences.

Preliminary EST data from this study as well as suppression subtractive hybridization results have identified several promising gene candidates (Table 1). In addition, we have recently developed a secondary screen for determining the expression patterns of candidate

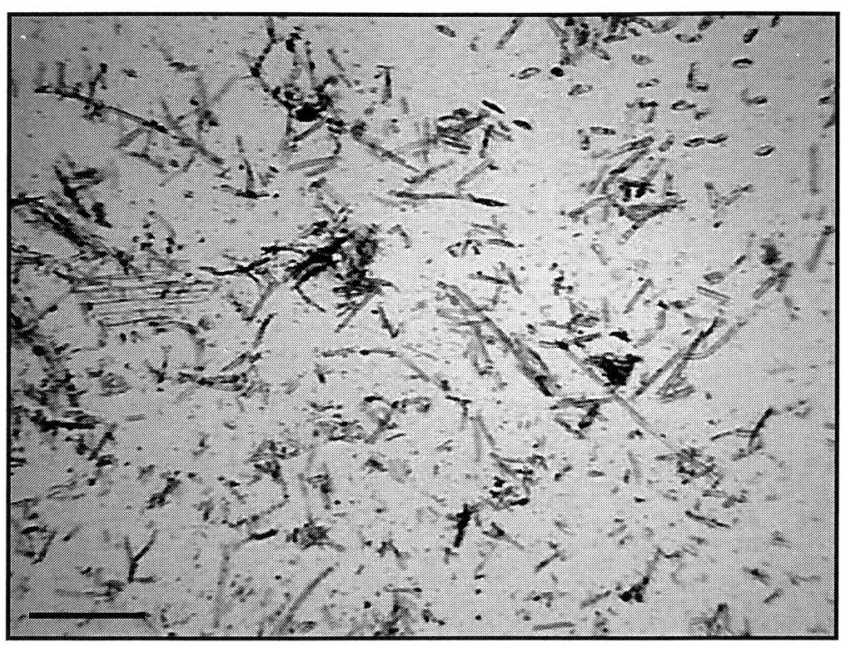

Fig. 2 Light micrograph of highly-enriched S. bicolor root hairs, isolated essentially as described by Bucher et al. ${ }^{69)}$ $\mathrm{Bar}=200 \mu \mathrm{m}$. sequences based on real-time PCR in the presence of the double stranded DNA-specific fluorophore, SYBR Green. ${ }^{68)}$ Figure 3 illustrates the utility of real time PCR for follow-up analyses of candidate sequences. By comparing PCR amplification signals using cDNAs

Table 1 Selected clones identified from suppression subtractive hybridization and/or EST analysis, potentially encoding sorgoleone biosynthetic enzymes. The predicted functions, scores, and $\mathrm{E}$ values were derived from the BLASTX output from the NCBI BLAST server (http: //www. ncbi.nlm.nih.gov/BLAST/).

\begin{tabular}{|l|l|c|l|l|}
\hline Clone I.D. & Predicted Function & Score & E value & Identity (\%) \\
\hline BS3_G07 & O-methyltransferase Maize (P47917) & 85.1 & $9.00 \mathrm{E}-17$ & $39 / 81(48)$ \\
\hline BS3_H11 & O-methyltransferase Maize (P47917) & 61.6 & $1.00 \mathrm{E}-09$ & $30 / 51(58)$ \\
\hline BS4R_H12 & O- methyltransferase Maize (P47917) & 97.8 & $2.00 \mathrm{E}-20$ & $49 / 89(55)$ \\
\hline BS6R_D08 & O- methyltransferase Maize (P47917) & 85.1 & $2.00 \mathrm{E}-16$ & $46 / 95(48)$ \\
\hline BS4R_C10 & $\begin{array}{l}\text { cytochrome P450 } \\
\text { Lolium rigidum (T06238) }\end{array}$ & 84 & $3.00 \mathrm{E}-16$ & $38 / 46(82)$ \\
\hline BS1R_D03 & $\begin{array}{l}\text { omega-3 fatty acid desaturase } \\
\text { Wheat (T06238) }\end{array}$ & 49.7 & $5.00 \mathrm{E}-06$ & $27 / 62(43)$ \\
\hline
\end{tabular}
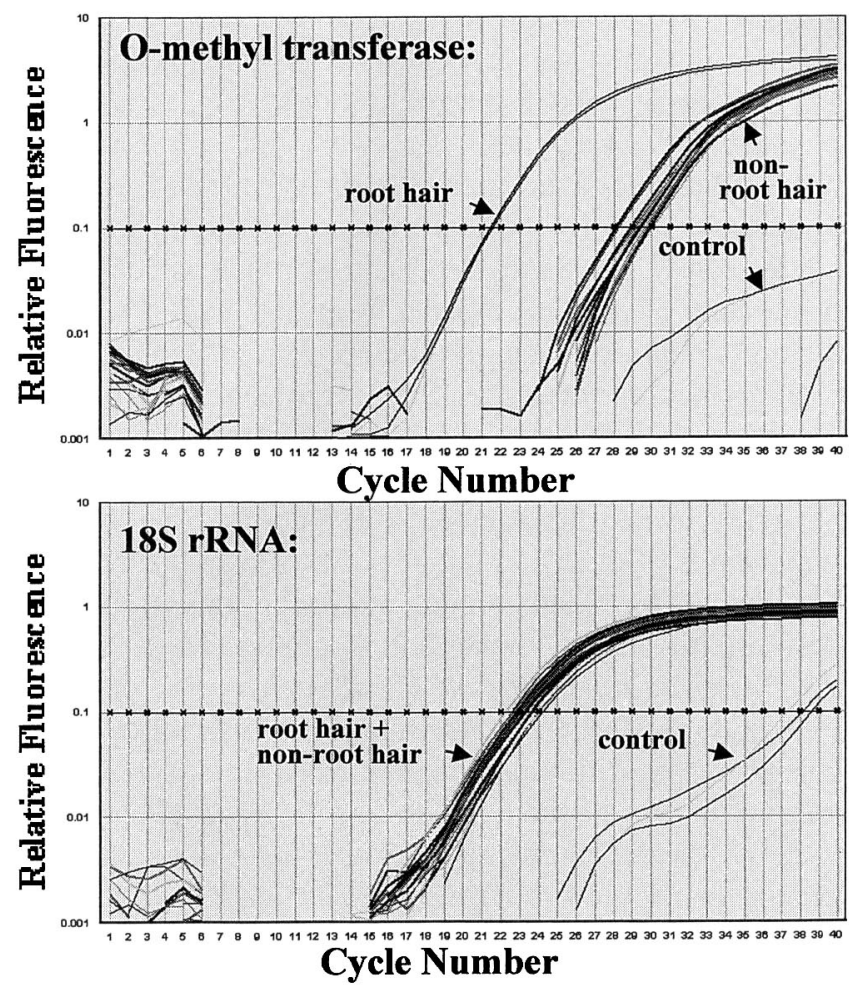

Fig. 3 Representative real-time PCR results generated using an $\mathrm{ABI} 5700$ sequence detection system and sequence-specific primers for a putative O-methyl transferase.

Upper panel: Sybr Green I signals generated from root hair cDNA vs. "non-root hair" (whole root, immature and mature leaf, stem, and developing panicle). Lower panel: same cDNAs used as in upper panel showing signals generated from an internal control gene (18S ribosomal RNA). 
prepared from six different $S$. bicolor tissues (root hair, whole root, immature leaf, mature leaf, stem, and panicle), the relative expression levels in these tissues can be rapidly determined. In the example shown (Fig. 3), a putative O-methyl transferase identified by both EST analysis and suppression subtractive hybridization is shown to exhibit highly root hair-preferential expression. Additional work is being performed to determine if this particular enzyme is capable of methylating sorgoleone precursors and structurally related molecules via heterologous expression in Escherichia coli. Ultimately, stably-transformed S. bicolor plants or root cultures will be employed to directly demonstrate the involvement of this gene in the sorgoleone biosynthetic pathway.

While efforts toward the genetic manipulation of allelochemical pathways are at a very preliminary stage, the tools are now at hand to make significant strides in this area. The likelihood that many, if not most, allelochemicals are synthesized in a cell type or organ-specific manner will greatly facilitate the isolation of genes involved in biosynthesis, as well as possible ancillary proteins involved in regulation, sequestration, or the rhizosecretion of allelochemicals. Moreover, the availability of additional molecular probes for specific allelochemical pathways will ultimately shed further light on the modes of regulation and environmental interactions involved, for which there is currently a paucity of information. ${ }^{70)}$

\section{NATURAL PRODUCTS USED AS HERBICIDES}

\subsection{Approaches}

Natural products may be used directly as pure compounds or as components of a crude preparation. For example, crude preparations of hydrolyzed maize gluten have been commercialized in the U.S. for weed management in turf. ${ }^{71)}$ Other crude preparations, such as olive oil mill wastes ${ }^{72)}$ and crambe (Crambe abyssinia) seed meal $^{73)}$ have been found to provide weed control. Such products require relatively little regulatory approval before they are sold. However, the large volume of most of these products needed for weed control in major crops, their relatively high cost, and the limited availability of the material restricts their use to niche markets that are unlikely to have any impact on synthetic pesticide use.

The other approach to using natural product directly for weed management is to use the pure compound as a herbicide or as a lead compound for the discovery of new herbicides. This strategy has had significant impact in terms of major herbicides and herbicide chemistries based on natural products.

\subsection{Discovery strategies}

The discovery process for natural product-based herbicides is somewhat different than that for synthetic herbicides. The most obvious difference is that, with the synthetic strategy, the structure of the compound is known, but determining the structure of a natural product found to have good biological activity can be difficult. The synthesis approach involves production of many compounds with doubtful biological activity, whereas, with the natural products approach, relatively few compounds are screened, but the probability of biological activity is much higher. Compounds from the synthetic approach are usually quite simple structurally, as the cost of production must be low for such a product. However, natural products can often be structurally complex, sometimes with multiple chiral centers. In such cases, structure-activity research can sometimes simplify and optimize the herbicidal activity. Unfortunately, the biological activity of a natural product has often been optimized by nature, so that efforts to improve its physicochemical properties or activity at the molecular target site are sometimes unsuccessful.

There are two discovery approaches with natural products. The first of these is to bioassay known natural products that have not been tested for phytoxicity. Relatively few of the natural products reported in the literature have been tested for herbicidal activity. However, most of this type of testing has not been reported. One can randomly test any natural product that can be obtained, or the chemical structure of known compounds can provide clues that suggest the compound might be a phytotoxin. For example, the structure of several natural triketone and triketone-like compounds indicated that they would be good inhibitors of HPPD. ${ }^{55)}$ Analogues of plant biosynthetic pathway intermediates are likely candidates as phytotoxins because of the probability that they will be inhibitors of critical enzymes for survival of the weed. For example, 2,4-anhydro-D-glucitol, a metabolite of Fusarium solani, is an analogue of fructose. After it is phosphorylated, it is both a phytotoxin and an inhibitor of fructose-1,6-bisphosphate aldolase. ${ }^{74)}$ Previous findings of toxicity against organisms other than plants also provide a clue that a compound could be herbicidal. For example, the antimalarial activity of artemisinin was the basis for testing it as a phytotoxin. ${ }^{75}$ Artemisinin and some of its natural product analogues are relatively potent phytotoxins. ${ }^{76,77)}$

Most natural product discovery involves bioassaydirected isolation of compounds of interest. There are hundreds of thousands, if not millions, of potential sources of natural products, few of which have been adequately tested evaluated for phytotoxin production. Considering the amount of work needed for bioassaydirected isolation, a random sampling of organisms may not be the most efficient discovery strategy. The pesticide industry has focused most of its attention on compounds from soil microbes found in exotic locations. Only a small fraction of soil microbes have been cultured, ${ }^{78)}$ so this is still a large, virtually untapped resource. However, we know little of how much dupli- 
cation exists between secondary metabolites from this type of source. Discovery of known compounds in new organisms is a costly problem in bioassay-directed isolation-based discovery schemes, ${ }^{79}$ ) and diminishing returns will become a bigger problem as bioprospecting for natural compounds progresses.

However, chemical ecology studies provide clues that might narrow the focus to fewer organisms. Just as ethnobotanical clues have been useful in the discovery of pharmaceutical uses of natural products, chemical ecology information can predict which organisms might generate phytotoxins. Most plant pathogens and all allelopathic plants (including lichens and algae) produce phytotoxins. Examples of potent plant pathogenproduced phytotoxins are tentoxin, cyperin, and AALtoxin. Several examples of plant pathogen-produced phytotoxins are provided below. Yet, relatively little discovery effort has been focused on plant pathogens as sources of phytotoxins.

Anatomical aspects of higher plants can provide useful clues as to phytotoxin production. Plants often sequester or secrete highly phytotoxic compounds in order to avoid autotoxicity. For example, artemisinin and other phytotoxins are sequestered in non-living parts of glandular trichomes. ${ }^{62)}$ Sorgoleone is produced only by root hair cells and is secreted from the cell as soon as it is produced. ${ }^{53)}$ In both cases, the molecular target site of the producing plant is apparently susceptible to the phytotoxin. We are currently involved in examination of trichome content and root exudates from other plant species.

\subsection{Examples}

There are only three commercial successes of the commercial use of pure natural compounds as herbicides. The Streptomyces spp. phytotoxins phosphinothricin and bialaphos are the only glutamine synthetaseinhibiting herbicides on the market. Phosphinothricin is sold as a chemically synthesized product, glufosinate, while bialaphos is the only herbicide produced by fermentation. These two compounds are the only commercial herbicides that target glutamine synthetase. ${ }^{80}$ ) Pelargonic acid (Fig. 4), a naturally occurring fatty acid, is sold for weed control in turf. ${ }^{81)}$ It has a very limited market.

The triketone herbicides were derived from the natural allelochemical, leptospermone (Fig. 4), an allelochemical produced by the bottlebrush shrub (Callistemon spp.). ${ }^{82}$ Sulcotrione (Fig. 4) and other triketone herbicides derived from this source are now marketed. The compounds are phytotoxic by inhibition of HPPD. Other natural products with triketone and benzoquinone structures, such as usnic acid (Fig. 4) and sorgoleone (Fig. 1) are also potent inhibitors of HPPD. ${ }^{55,83)}$

Cinmethylin (Fig. 4) is a close analogue of the allelochemical, 1,4-cineole (Fig. 4), although there has been no

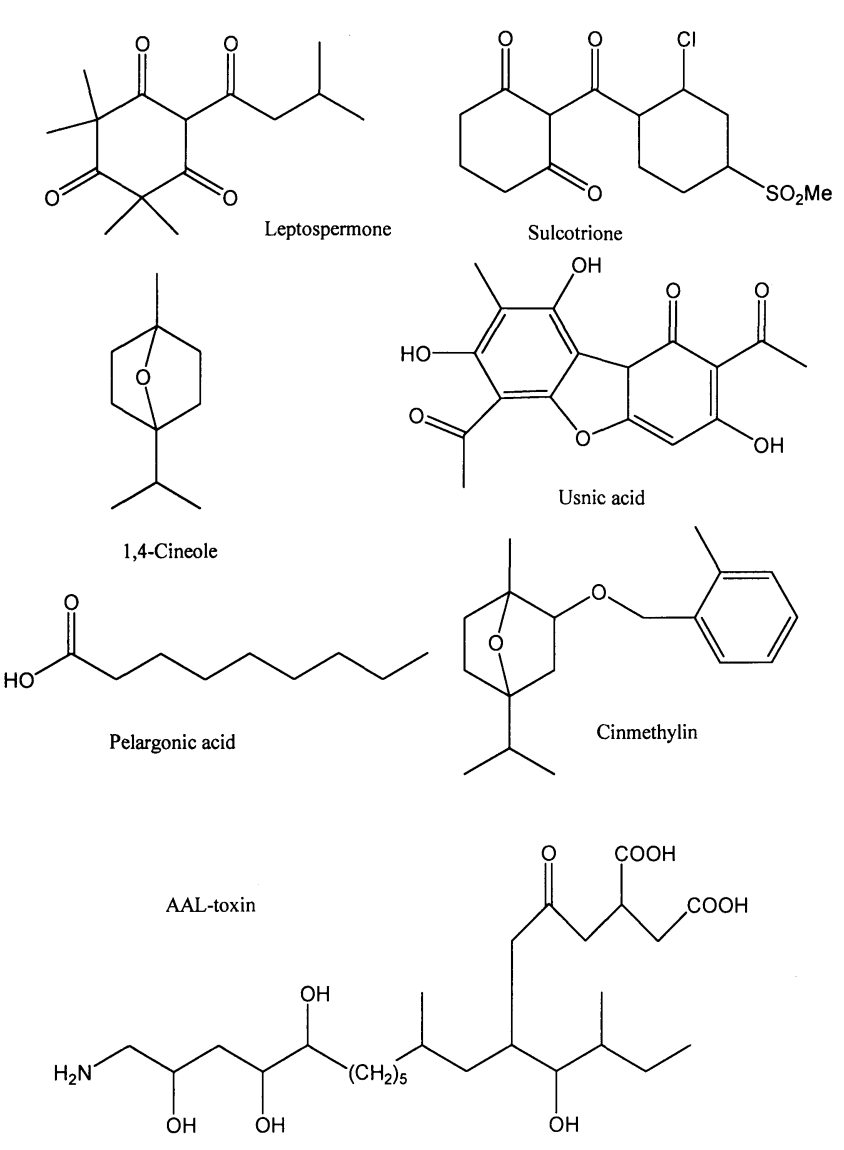

Fig. 4 Structures of some of the natural phytotoxins mentioned in the text.

claim that it was derived from this natural phytotoxin. 1,4-cineole is a potent inhibitor of asparagine synthetase (AS), ${ }^{84)}$ a new molecular target site. Cinmethylin has no in vitro effects on AS, although it is apparently metabolically converted to a hydroxy-1,4-cineole, which is a potent inhibitor of the enzyme. The more common plant-derived monoterpene, 1,8-cineole has no effect on $\mathrm{AS},{ }^{84)}$ and its phytotoxicity appears to be due to effects on mitosis. ${ }^{85)}$

Certain pathovars of Alternaria alternata produce AAL-toxin (Fig. 4), one of the strongest natural phytotoxins, ${ }^{86)}$ although it was originally reported as a host-selective phytotoxin, affecting only certain tomato varieties. ${ }^{87}$ It is an analogue of the sphingoid base precursors of ceramide synthase, and apparently causes rapid and dramatic accumulation of these compounds in plant tissues by inhibition of this enzyme. ${ }^{88)}$ Treatment of plants with the sphingonine and phytosphingosine, the compounds that accumulate in the presence of AALtoxin, causes symptoms very similar to those caused by AAL-toxin. ${ }^{89}$ These results and others have led us to hypothesize that AAL-toxin causes plant death by inhibition of ceramide synthesis, thereby causing massive accumulation of membrane-disrupting sphingoid bases. ${ }^{90)}$ 
Indeed, both inhibitors of ceramide synthase and sphinganine cause similar cell death in mammalian cells, ${ }^{91}$ ) although this process is thought to be apoptosis mediated. Unfortunately, AAL-toxin is highly toxic to mammals and structure-activity manipulation has not resulted in producing an analogue with significantly reduced mammalian toxicity, while retaining strong phytotoxicity. ${ }^{90)}$

These are only a small fraction of the natural products known to have phytotoxicity sufficient for herbicide use. What little is known of their molecular target sites suggests that they are offer good opportunities for the discovery of new herbicide modes of action. ${ }^{1)}$

\section{SUMMARY}

In summary, natural products, either as herbicides or as cover crop- or crop-generated allelochemicals, offer important new options for weed management. New technologies and strategies offer to bring these possibilities to fruition in the near future. The process of bioassay-directed isolation has become more automated and faster, thereby alleviating some of the obstacles to natural product-based herbicide discovery strategies. The tools of molecular biology provide a means of generating crops that produce sufficient allelochemicals for weed management with greatly reduced synthetic herbicide input.

\section{REFERENCES}

1) S. O. Duke, F. E. Dayan and J. G. Romagni: Crop Protect. 19, 583-589 (2000).

2) S. O. Duke, F. E. Dayan and J. G. Romagni: Weed Res. 40, 99-111 (2000).

3) S. O. Duke, S. R. Baerson, F. E. Dayan, I. A. Kagan, A. Michel and B. E. Scheffler: "Enhancing Biocontrol Agents and Handling Risks," ed. by M. Vurro, J. Gressel, T. Butt, G. E. Harman, A. Pilgeram, R. J. St. Leger and D. L. Nuss, IOS Press, Amsterdam, pp. 96-105, 2001.

4) S. O. Duke, F. E. Dayan, A. M. Rimando, K. K. Schrader, G. Aliotta, A. Oliva and J. G. Romagni: Weed Sci. 50, 138151 (2002).

5) H. P. Singh, D. R. Batish and R. K. Kohli: J. Crop Prod. 4, 1-41 (2001).

6) L. B. Jensen, B. Courtois, S. Lishuang, L. Zhikang and M. Olofsdotter: Agron. J. 93, 21-26 (2001).

7) H. Wu, H. Pratley, D. Lemerle and T. Haig: Weed Res. 39, 171-180 (1999).

8) J. V. Lovett and A. H. C. Hoult: Amer. Chem. Soc. Symp. Ser. 582, 170-183 (1995).

9) L. Overland: Amer. J. Bot. 53, 423-432 (1966).

10) D. G. Shilling, A. D. Worsham and D. A. Danehower: Weed Sci. 34, 738-744 (1986).

11) D. L. Liu and J. V. Lovett: "Alternatives to the Chemical Control of Weeds," 1990 Proceedings of an International Conference, Rotuora, New Zealand, July, 1989, FRI Bulletin 155 , ed. by C. Bassett, L. J. Whitehouse and J. A. Zabkiewicz, Ministry of Forestry, Rotuora, New Zealand,
$85-92$.

12) J. V. Lovett and A. H. C. Hoult: Amer. Chem. Soc. Symp. Ser. 582, 170-183 (1995).

13) H. Börner: Bot. Rev. 26, 393-424 (1960).

14) A. Baghestani, C. Lemieux, G. D. Leroux, R. Baziramakenga and R. R. Simard: Weed Sci. 47, 498-504 (1999).

15) A. D. Hanson, P. L. Traynor, K. M. Ditz and D. A. Reicosky: Crop Sci. 21, 726-730 (1981).

16) A. H. C. Hoult and J. C. Lovett: J. Chem. Ecol. 19, 22452254 (1993).

17) H. Yoshida, H. Tsumuki, K. Kanehisa and L. J. Corcuera: Phytochemistry 34, 1011-1013 (1993).

18) J. V. Lovett, A. H. C. Hoult and O. Christen: J. Chem. Ecol. 20, 1945-1954 (1994).

19) D. L. Liu and J. V. Lovett: J. Chem. Ecol. 19, 2231-2244 (1993).

20) D. L. Liu and J. V. Lovett: J. Chem. Ecol. 19, 2217-2230 (1993).

21) V. Kat and R. J. Froud-Williams: 1999 Brighton Crop Protection Conference-Weeds 2, 579-580 (1999).

22) B. N. Barria, S. V. Copaja and H. M. Niemeyer: Phytochemistry 31, 89-91 (1992).

23) G. G. Nagabhushana, A. D. Worsham and J. P. Yenish: Allelopathy J. 8, 133-146 (2001).

24) Y. Fujii: J. Crop Prod. 4, 257-275 (2001).

25) J. P. Barnes and A. R. Putnam: J. Chem. Ecol. 9, 1045-1057 (1993).

26) F. J. Pérez and J. Ormeño-Nuñez: J. Chem. Ecol. 17, 10371043 (1991).

27) F. J. Pérez and J. Ormeño-Nuñez: Weed Res. 33, 115-119 (1993).

28) M. Pethõ: Acta Agron. Hung. 41, 167-175 (1992).

29) J. P. Barnes and A. R. Putnam: J. Chem. Ecol. 13, 889-906 (1987).

30) R. W. Gagliardo and W. S. Chilton: J. Chem. Ecol. 18, 1683-1691 (1992).

31) A. Friebe, I. Wieland and M. Schulz: Angew. Bot. 70, 150154 (1996).

32) J. P. Barnes and A. R. Putnam: Weed Sci. 34, 384-390 (1986).

33) R. H. Dilday, P. Nastasi and R. J. Smith: "Sustainable Agriculture for the Great Plains," Symposium Proceedings, USDA, ARS, ARS-89, ed. by J. D. Hanson, M. J. Shaffer, D. A. Ball and C. V. Cole, USDA, ARS, Beltsville, MD, pp. 193-201, 1991.

34) K. U. Kim and D. H. Shin: "Allelopathy in Rice," ed. by M. Olofsdotter, International Rice Research Institute, Manila, Philippines, pp. 39-43, 1998.

35) M. Olofsdotter, D. Wang and D. Navarez: "Recent Advances in Allelopathy, Vol. I, A Science for the Future," ed. by F. A. Macias, J. C. G. Galindo, J. M. G. Molinillo and H. G. Cutler, Servicio de Publicaciones - Universidad de Cadiz, Spain, pp. 383-390, 1999.

36) Y. Fujii: Proc. Plant Growth Regul. Soc. 22, 14-18 (1995).

37) D. Navarez and M. Olofsdotter: Proc. 2nd Internal Weed Control Conf., Copenhagen, Denmark, 4, 1285-1290 (1996).

38) R. Mattice, T. Lavy, D. Skulman and R. Dilday: "Allelopathy in Rice," ed. by M. Olofsdotter, International Rice Research Institute, Manila, Philippines, pp. 81-98, 1998.

39) K. W. Kim and K. U. Kim: "Proc. International Workshop on Rice Allelopathy," Institute of Agricultural Science and 
Technology, Kyungpook National University, Tageu, Korea, pp. 73-84, 1998.

40) I. M. Chung, J. K. Ahn and S. J. Yun: Can. J. Plant Sci. 81, 815-819 (2001).

41) W. Lin, H. He, Y. Guo, Y. Liang and F. Chen: Yingyong Shengtai Xuebao 12, 871-875 (2001).

42) A. M. Rimando, M. Olofsdotter, F. E. Dayan and S. O. Duke: Agron. J. 93, 16-20 (2001).

43) T. Kato, M. Tsunakawa, N. Sasaki, H. Aizawa, K. Fujita, Y. Kitahara and N. Takahashi: Phytochemistry 16, 45-48 (1977).

44) M. Olofsdotter, M. Rebulanan, A. Madrid, W. Dali, D. Navarez and D. C. Olk: J. Chem. Ecol. 28, 229-242 (2002).

45) C. Kong, X. Xu, F. Hu, X. Chen, B. Ling and Z. Tan: Chin. Sci. Bull. 47, 839-843 (2002).

46) T. Kato, C. Kabuto, N. Sasaki, M. Tsunagawa, H. Aizawa, K. Fujita, Y. Kato and Y. Kitahara: Tetrahedron Lett. 39, 3861-3864 (1973).

47) M. Tsunakawa, A. Ohba, N. Sasaki, C. Kabuto, T. Kato, Y. Kitahara and N. Takahashi: Chem. Lett. 11, 1157-1158 (1976).

48) C. W. Lee, K. Yoneyama, M. Ogasawara, Y. Takeuchi and M. Konnai: Proc. 17th Asian-Pacific Weed Science Society Conference, Bangkok, Thailand, Nov. 22-27 (1999).

49) H. Kato-Noguchi: Plant Prod. Sci. 5, 8-10 (2002).

50) L. A. Weston, C. I. Nimbal and J. Jeandet: "Principles and Practices in Plant Ecology, Allelochemical Interactions," ed. by Inderjit, K. M. M. Dakshini and C. L. Foy, CRC Press, Boca Raton, Florida, pp. 467-477, 1999.

51) A. M. Rimando, F. E. Dayan, M. A. Czarnota, L. A. Weston, S. O. Duke: J. Nat. Prod. 61, 927-930 (1998).

52) M. A. Czarnota, R. N. Paul, F. E. Dayan, C. I. Nimbal and L. A. Weston: Weed Technol. 15, 813-825 (2001).

53) F. A. Einhellig, J. A. Rasmussen, A. M. Hejl and I. F. Souza: J. Chem. Ecol. 19, 369-375 (1993).

54) J. C. Streibig, F. E. Dayan, A. M. Rimando and S. O. Duke: Pestic. Sci. 55, 137-146 (1999).

55) G. Meazza, B. E. Scheffler, M. R. Tellez, A. M. Rimando, J. G. Romagni, S. O. Duke, D. Nanayakkara, I. A. Khan, E. A. Abourashed, F. E. Dayan: Phytochemistry 59, 282-288 (2002).

56) S. O. Duke, B. E. Scheffler, F. E. Dayan and E. Ota: Weed Technol. 15, 826-834 (2001).

57) S. O. Duke, B. E. Scheffler, F. E. Dayan and W. E. Dyer: Amer. Chem. Soc. Symp. Ser. 829, in press (2002).

58) B. E. Scheffler, S. O. Duke, F. E. Dayan and E. Ota: Rec. Adv. Phytochem. 35, 257-274 (2000).

59) M. Frey, P. Chomet, E. Glawischnig, C. Stettner, S. Grün, A. Winklmair, W. Eisenreich, A. Bacher, R. B. Meeley, S. P. Briggs, K. Simcox and A. Gierl: Science 277, 696-699 (1997).

60) R. H. Hamilton: Weeds 12, 27-30 (1964).

61) L. Diatchenko, Y.-F. C. Lau, A. P. Campbell, A. Chenchik, F. Moquadam, B. Huang, S. Lukyanov, K. Lukyanov and N. Gurskaya: Proc. Natl. Acad. Sci. USA 93, 6025-6030 (1996).

62) P. Liang and A. B. Pardee: Science 257, 967-971 (1992).

63) M. V. Duke, R. N. Paul, H. K. ElSohly, G. Sturtz and S. O. Duke: J. Plant Sci. 155, 365-373 (1994).

64) M. R. Tellez, C. Canel, A. M. Rimando and S. O. Duke: Phytochemistry 52, 1035-1040 (1999).

65) M. D. Adams, J. M. Kelley, J. D. Gocayne, M. Dubnick, M. H. Polymeropoulos, H. Xiao, C. R. Merril, A. Wu, B. Olde and R. F. Moreno: Science 252, 1651-1656 (1991).

66) B. M. Lange, M. R. Wildung, E. J. Stauber, C. Sanchez, D. Pouchnik and R. Croteau: Proc. Natl. Acad. Sci. USA 97, 2934-2939 (2000).

67) D. H. Netzley and L. G. Butler: Crop Sci. 26, 776-778 (1986).

68) M. Hiratsuka, Y. Kishikawa, K. Narahara, T. Inoue, S. I. Hamdy, Y. Agatsuma, Y. Tomioka and M. Mizugaki: Anal. Biochem. 289, 300-303 (2001).

69) M. Bucher, B. Schroeer, L. Willmitzer and J. W. Riesmeier: Plant Mol. Biol. 35, 497-508 (1997).

70) F. A. Einhellig: Amer. Chem. Soc. Symp. Ser. 582, 1-24 (1995).

71) R. E. Gough and R. Carlstrom: HortScience 34, 269-270 (1999).

72) G. Aliotta, G. Cafiero, V. De Feo, B. Di Blasio, R. Iacovino and A. Oliva: Curr. Top. Phytochem. 3, 167-177 (2000).

73) S. F. Vaughn and M. A. Berhow: J. Chem. Ecol. 24, 11171126 (1998).

74) F. E. Dayan, A. M. Rimando, M. R. Tellez, B. E. Scheffler, T. Roy, H. K. Abbas and S. O. Duke: Z. Naturforsch. in press (2002).

75) S. O. Duke, K. C. Vaughn, E. M. Croom, Jr. and H. N. Elsohly: Weed Sci. 35, 499-505 (1987).

76) S. O. Duke, R. N. Paul and S. M. Lee: Amer. Chem. Soc. Symp. Ser. 380, 318-334 (1988).

77) F. E. Dayan, A. Hernandez, S. N. Allen, R. M. Moraes, J. A. Vroman, M. A. Avery and S. O. Duke: Phytochemistry 50, 607-614 (1999).

78) A. Felske, H. Rheims, A. Wolternick, E. Stackebrandt and A. D. Akkermans: Microbiology 143, 2983-2989 (1997).

79) S. W. Ayer, B. G. Ksaac, D. M. Krupa, K. E. Crosby, L. J. Letendre and R. J. Stonard: Pestic. Sci. 27, 221-223 (1989).

80) J. Lydon and S. O. Duke: "Plant Amino Acids, Biochemistry and Biotechnology," ed. by B. K. Singh, New York, pp. 445-464, 1999.

81) G. P. Irzyk, P. Zorner and A. Kern: Weed Sci. Soc. Amer. Abstr. 37, 103 (1997).

82) D. L. Lee, M. P. Prisbylla, T. H. Cromartie, D. P. Dagarin, S. E. Howard, W. M. Provan, M. K. Ellis, T. Fraser and L. C. Mutter: Weed Sci. 45, 601-609 (1997).

83) J. G. Romagni, G. Meazza, N. P. D. Nanyakkara and F. E. Dayan: FEBS Lett. 480, 301-305 (2000).

84) J. G. Romagni, S. O. Duke and F. E. Dayan: Plant Physiol. 123, 725-732 (2000).

85) J. G. Romagni, S. N. Allen and F. E. Dayan: J. Chem. Ecol. 26, 303-313 (2000).

86) H. K. Abbas, T. Tanaka, S. O. Duke and C. D. Boyette: Weed Technol. 9, 125-130 (1995).

87) S. D. Clouse and D. C. Gilchrist: Phytopathology 77, 80-82 (1987).

88) H. K. Abbas, T. Tanaka, S. O. Duke, J. K. Porter, E. M. Wray, L. Hodges, A. E. Sessions, E. Wang, A. H. Merrill and R. T. Riley: Plant Physiol. 106, 1085-1093 (1994).

89) T. Tanaka, H. K. Abbas and S. O. Duke: Phytochemistry 33, 779-785 (1993).

90) H. K. Abbas, S. O. Duke, W. T. Shier and M. V. Duke: "Advances in Microbial Toxin Research and Its Biotechnological Exploitation," ed. by R. K. Upadhyay, Kluwer Academic/Plenum Publ., London, pp. 211-229, 2002.

91) E. H. Ahn and J. J. Schroeder : Exp. Biol. Med. 227, 345353 (2002). 